Soni, K., \& Desai, M. (2021). Stock Prices: Effect of Behavioral Biases on Investor's Mindset in Gujarat State, India. Copernican Journal of Finance \& Accounting, 10(1), 67-79. http://dx.doi. org/10.12775/CJFA.2021.004

\author{
KRUNAL SONI* \\ SDJ International College \\ Maulik Desal ${ }^{* *}$ \\ K S School of Business Management
}

\title{
STOCK PRICES: EFFECT OF BEHAVIORAL BIASES ON INVESTOR'S MINDSET IN GUJARAT STATE, INDIA
}

Keywords: behavior of investors, company information, location of the company, IPO issue.

\section{J E L Classification: G41.}

\begin{abstract}
Stock market performances has been observed through a good deal of literature out of which it has been found out that the behavior of investors is affected through many parameters exist in the market like occurrence of any sudden event or influence of Individual advice apart from the past behavior of the stock which is called rational information regarding stock performances as per the traditional finance theory. The main aim of this paper is to identify the mediating effect among various types of information available in the market for investors to invest their money into the stock market as a part of different behavioral biases in the Gujarat State, India. Three types of constructs have been derived as a part of exploratory research design for this study by applying exploratory factor analysis (EFA) which are Company History, IPO issues and Location benefit of the company out of the different variable taken for the study. Struc-
\end{abstract}

Date of submission: March 12, 2021 ; date of acceptance: May 2, 2021.

* Contact information: sonikrunal07@gmail.com, SDJ International College, Surat, phone: +91-9979540163; ORCID ID: https://orcid.org/0000-0002-5024-1086.

** Contact information: desaimaulik@hotmail.com, K S School of Business Management, Ahmedabad, phone: +91-9824501950; ORCID ID: https://orcid.org/0000-00032887-5856. 
tural Equation modelling (SEM) techniques have been applied to check the mediating effect among these three constructs. The study has been concluded that Company information is an indirect construct, IPO issue is a dependent construct and Location of the company is a mediating construct which is revealing that there is a significant impact of Company information on the IPO issue done by any corporate in the market. IPO issue can also be affected by the Location of the company which has the mediating effect on it.

\section{INTRODUCTION}

Normally the trend of stock market can be identified with the help of investor's decision under the different circumstances. In the past, traditional finance concept was existing to track the behavior of investors in the market which also assumes that the investors behave rationally which means that the decision of the investors to invest in the stock market is largely depend upon the belief and the recent information prevail in the market. In the recent time the behavior of investor concept is considered to the psychological and sociological concept theories with finance. This concept was first recognized by the Daniel Kahneman and Vernon Smith, the Nobel Prize getter in the subject of economics in the year 2002. Basically, financing is based on how financial decisions of individuals and companies are affected by psychology in financial environments Kim and Nofsinger (2008). This was the period when the researcher started to felt that investors were occasionally irrational and due to which their decisions might be biased due to the incompetence to process complex information, and the lack of mental knacks. Therefore, investment decisions are sometimes based on shortcuts of information handling and emotional files. This paper tries to find out the information related to company, IPO and Location of the company on the behavior of investors in the stock market of Gujarat state in India which have a direct impact regarding return of the investors.

\section{RESEARCH METHODOLOGY AND RESEARCH PROCESS}

\section{Objectives of the Study}

To study the impact of various behavioral biases in the mind of investors on the selection of particular stock by them in the stock market. 


\section{Area of the Study}

The area of the responses have been restricted to the Gujarat state only to check the psychological impact of numerous behavioral biases on their mind while making choices for particular stock in the stock market.

\section{Sample Size}

To check the Effect of various behavioral biases on the mindset of investor's in the Gujarat State, India, total 215 samples have been taken in the study from the respondents those who have the experience to make an investment in the stock market.

\section{Sources of Data}

For the benefit of this study, the data has been collected from the experienced investors from the stock market with the help of primary study with the help of designing structured questionnaire.

\section{Direct effect and Indirect effect through Mediation}

Hayes' Approach says that to prove mediation effect, first indirect effect should be significant otherwise there is no mediation effect among the construct.

Figure 1. Example of Mediation Effect

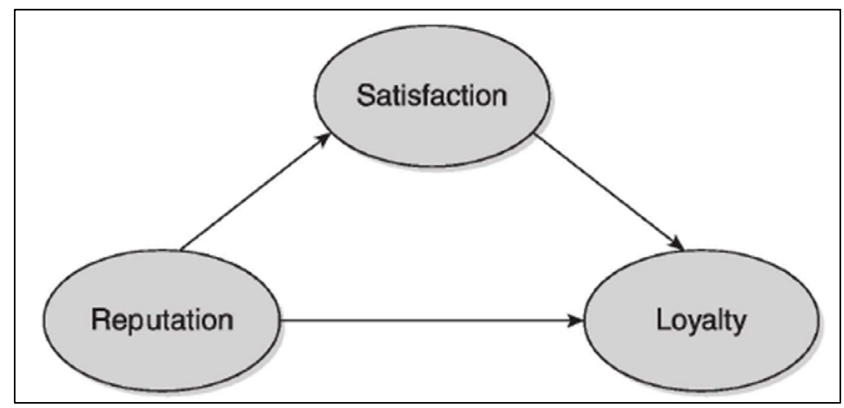


In the above figure 1, it can be seen that the reputation represents the indirect variable for the study, Loyalty represents the direct variable for the study it means there is a significant impact of reputation on the loyalty of the employee which proves the direct effect of the model. Apart from these two variables, there is a satisfaction variable which represents the mediation variable which indicates that to prove the impact of reputation of the loyalty, there is a partial impact of satisfaction of employee on their loyalty.

\section{Endogenous, Exogenous and Moderating Variable of the study}

Company Information is an exogenous variable, IPO issue of the company is endogenous variable and location of the company is mediating variable for the company. Convergent and Discriminant validity of the study: Convergent validity which is a measure which is used in many field of studies to check that various measures of construct that are theoretically related with each other or not. One can confirm the convergent validity among different variable of construct by referring Construct Reliability (CR) and Average Variance Explained value (AVE). The standard criteria for Convergent Validity is CR $>0.7, A V E>0.5$, CR > AVE and MaxR(H) > MSV (Hair, Hult, Ringle \& Sarstedt, 2016).

\section{Formula for the Measurement:}

$$
\begin{aligned}
& \mathbf{C R}=\left(\sum \mathrm{x}\right)^{2} /\left(\sum \mathrm{x}\right)^{2}+\sum(\delta) \\
& \mathbf{A V E}=\left(\sum \mathrm{x}\right)^{2} / \mathrm{N} \\
& \mathbf{M S V}=\text { Highest of }(\mathrm{FL})^{2} \text { out of the one construct } \\
& \operatorname{MaxR}(\mathbf{H})=(\mathrm{AVE})^{2}
\end{aligned}
$$

Discriminant validity is used to check whether the variable of the construct which is related to each other are actually unrelated. The criteria of Discriminant validity is already depicted in table 4 below in the result and discussion. 


\section{LITERATURE REVIEW AND HYPOTHESIS DESIGN}

\section{Behavioral Biases Parameters}

Keswani, Dhingra and Wadhwa (2019) in his paper they had depicted that the behavior of investors in the National stock exchange market (NSE) is getting influenced by so many factors from the market like price changes of the stock, market information, over confidence, Anchoring, Availability bias, past trends of the stock, etc. Sarin and Sidana (2017) showcased that initial public offering (IPO) is one of the most outstanding issues of a firm which is also called, "going public" which is generally come out by the large scale industries. The major search of this paper is to identity the analysis of IPO grading on the behavior of investors in the Indian stock market which is very significant. Saravanan and Satish (2014) focused on to check the significant impact of credit ratings given to IPO of any listed companies and its effect on the daily return of investors with respect to the changing in the behavior of investors, and they had concluded there is positive impact on the behavior of investors in the stock market with respect to the credit rating, and IPO information.

Hypothesis for this study is:

$\mathrm{H}_{0}$ : There is no significant impact of various behavioral biases on the mind of investors in the Gujarat State for selection of particular stock.

$\mathrm{H}_{1}$ : There is no significant impact of various behavioral biases on the mind of investors in the Gujarat State for selection of particular stock.

\section{Factors of Behavioral Biases}

Grinblatt and Keloharju (2001) this paper also described that investors are more likely to hold, buy and sell those companies stock which are located near their location within 100 kilometers which is familiar with investors native language and also the governing body are from the same cultural and religious background. These factors have the impact on the behavior of both the types of investors in the stock market, i.e. households and less savvy institutions with the help of Regression analysis. Head, Ries and Swenson (1995) suggest that firms in the same industry with same locations because proximity generates positive externalizes or 'agglomeration effects'. Under this view, chance events and the government encouragements can have a permanent influence on the 
geographical pattern of manufacturing. However, most confirmation on the causes and degree of industry localization has been based on stories, rather than statistics. This paper examines the location choices of 751 Japanese manufacturing plants built in the United States since 1980. Conditional logit estimates support the hypothesis that industry-level agglomeration benefits play an important role in location decisions.

\section{Structural Equation Modeling}

Structural Equation Modelling is a popular statistical technique for testing and estimating causal relations using a combination of statistical data and qualitative causal assumptions, which are typically based on a theory. This technique is widely used by social scientists for theory testing and development. SEM is a combination of factor analysis and multiple-regression and it includes path analysis, and confirmatory factor analysis (Noar, 2003).

\section{ANALYSIS OF DATA AND RESULT}

Table 1. Reliability Table

\begin{tabular}{|c|c|}
\hline \hline Cronbach's Alpha & N of Items \\
\hline 0.935 & 15 \\
\hline \hline
\end{tabular}

S o u r c s : research outcome.

Table 1, indicates the reliability testing of Cronbach's Alpha which is 0.935 , it indicates the better reliability of the scale data. The collected primary response data is analyzed by different statistical methods. The analysis begins with advancement of the measurement scale counting all the construct restrained in the study. The measurement model is scrutinized for the inner consistency reliability and the attendance of necessary convergent and discriminant validity in the scale. The reliability of the mechanism is further obligatory to guarantee the presence of scale validity. The presence of reliability of an instrument specifies that the instrument affords the stable and consistent scores from a test. There are numerous methods to study the reliability of an instrument; however, in this study the internal consistency reliability is tested with the assistance 
of Cronbach alpha. The internal consistency of a set of items or statements in the scale is the degree to which these items are homogeneous. Internal consistency reliability of an instrument can be inspected with the help of Cronbach's alpha (Kim, Lee, Kim, Lim, Shin, Chung, Yu, \& Hong, 2002). The value of Cronbach's Alpha greater than 0.7 are benchmark criteria, greater than 0.8 are measured well, and more than 0.9 are measured to reflect extraordinary internal consistency (Cronbach, 1951). In the study the overall Cronbach's alpha value for 15items (variables) was found to be 0.935 representing that the recognized items were reliable.

Table 2. Factor Loading with KMO \& Bartlet Test of Sphericity for Factors of Behavioral Biases

\begin{tabular}{|c|c|c|c|c|c|c|}
\hline Variable & Com & $\begin{array}{c}\text { Varimax } \\
\text { Rotated Comp. }\end{array}$ & Factor & Variance Expl & Eigen Value & Normality \\
\hline SEI & 0.621 & 0.749 & \multirow{7}{*}{$\begin{array}{c}\text { Factor1: } \\
\text { Company } \\
\text { Information }\end{array}$} & \multirow[t]{7}{*}{26.286} & \multirow[t]{7}{*}{6.175} & \multirow[t]{7}{*}{0.004} \\
\hline LMI & 0.639 & 0.777 & & & & \\
\hline $\mathbf{R F}$ & 0.629 & 0.766 & & & & \\
\hline CRA & 0.625 & 0.726 & & & & \\
\hline BA & 0.313 & 0.460 & & & & \\
\hline $\mathrm{CH}$ & 0.700 & 0.741 & & & & \\
\hline PB & 0.520 & 0.671 & & & & \\
\hline APC & 0.631 & 0.750 & \multirow{5}{*}{$\begin{array}{l}\text { Factor 2: } \\
\text { IPO Issue }\end{array}$} & \multirow{5}{*}{23.373} & \multirow{5}{*}{2.123} & \multirow{5}{*}{$0.200 *$} \\
\hline PI & 0.745 & 0.814 & & & & \\
\hline OPI & 0.745 & 0.812 & & & & \\
\hline $\mathrm{COI}$ & 0.745 & 0.775 & & & & \\
\hline MMSA & 0.548 & 0.674 & & & & \\
\hline II & 0.726 & 0.837 & \multirow{3}{*}{$\begin{array}{l}\text { Factor 3: } \\
\text { Location }\end{array}$} & \multirow[t]{3}{*}{14.085} & \multirow[t]{3}{*}{1.264} & \multirow[t]{3}{*}{0.016} \\
\hline CPMF & 0.690 & 0.830 & & & & \\
\hline INFRA & 0.683 & 0.823 & & & & \\
\hline \multicolumn{4}{|c|}{ Total variance Explained } & \multicolumn{3}{|c|}{63.744} \\
\hline \multicolumn{4}{|c|}{ KMO Test for Sampling Adequacy } & \multicolumn{3}{|c|}{0.850} \\
\hline \multicolumn{4}{|c|}{ Bartlett Test for Spherisity Sig. Value } & \multicolumn{3}{|c|}{$0.000 * *$} \\
\hline
\end{tabular}


Table 2, indicates the total factor loading by applying dimension reduction techniques in social science research. KMO test is showing the result of 0.850 sampling adequacy, and also the Bartlet test of Sphericity is $0.000^{* *}$ which is sufficient to run the factor loading. The result shows total three constructs have been extracted out of fifteen variables taken for the study to check the mediation effect between the constructs which has a significant impact on the behavior of investors in the stock market. The second column of table 2 represent the communalities of variable which represent how much particular variable supporting to the related construct in the relative percentage. The third column represent variance rotated component which describe that how the related variable contributing to the construct. Column of factor represents the total factors which have been extracted by applying dimension reduction techniques. Column five describe variance explained by each of the construct to support the study. In this study factor 1: company information have $26.286 \%$ of variance explained out of the total $63.744 \%$ of the total variance explained and same way IPO issue has $23.373 \%$ and location have $14.085 \%$ of total variance explained. Which also means that the total statement of likert scale which had been asked the respondent, these factor represent only $63.744 \%$ of the total score which means $36.256 \%$ of the data have been lost. Figure 1 indicates path diagram to represent the mediation effect of Location of the company to see the impact of company information as an independent variable on the IPO issues of the company as a dependent variable which has the direct impact on the behavior of the investor at the time of investing money in the stock exchange.

Table 3. Convergent Validity Measure for Model fit

\begin{tabular}{|l|c|c|c|c|}
\hline \hline \multicolumn{1}{|c|}{ Variable } & CR & AVE & MSV & MaxR(H) \\
\hline \hline $\begin{array}{l}\text { Company } \\
\text { Information }\end{array}$ & 0.872 & 0.498 & 0.548 & 0.706 \\
\hline $\begin{array}{l}\text { IPO } \\
\text { Issue }\end{array}$ & 0.778 & 0.539 & 0.004 & 0.734 \\
\hline Location & 0.885 & 0.609 & 0.548 & 0.781 \\
\hline \hline
\end{tabular}

N o t e : CR = Construct Reliability, AVE = Average Variance Explained, MSV = Maximum Shared Variance, $\operatorname{MaxR}(\mathrm{H})=\operatorname{Maximum}$ Reliability $(\mathrm{H})$.

S o u r c e s: AMOS 20 Output. 
Figure 2. Structural Equation Modelling for Various Behavioral Biases

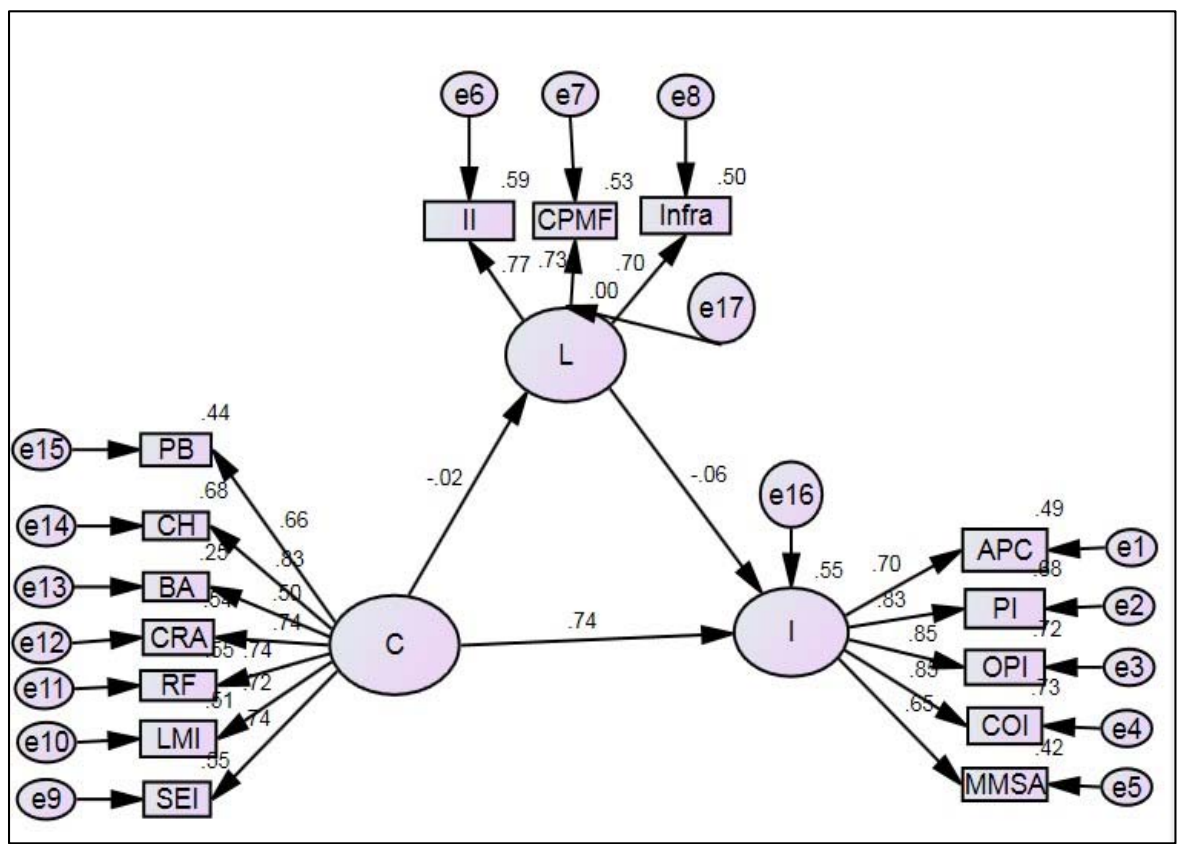

S o u r c e s: AMOS Output.

Table 3 describe that the study is fulfilling the criteria convergent validity, Composite reliability (CR) is of a construct in the measurement model is used to quantity its reliability as well as convergent validity. It provides a more reflective approach of overall reliability and analyses the reliability of the construct itself including the stability and correspondence of construct (Hair et al., 2016). The ideal criteria for CR $>0.7$, for "Company information" it is 0.872 , "IPO Issue" is 0.778 and "Location" is 0.885 indicating that all constructs representing the different behavioural biases in the measurement model have good reliability. It can be obviously stated that all the values of average variance extracted (AVE) is a measure of the amount of variance that is caught by a construct in relation to the amount of variance due to dimension error. The ideal criteria for is AVE $>0.5$ and CR $>$ AVE and MaxR(H) $>$ MSV.. use of CR is $>0.7$, all the Values of AVE $>0.5$, all the value of CR $>$ AVE and all the values of MaxR $(\mathrm{H})>\operatorname{MSV}$ which shows that all the three construct Company information, IPO issues and Location of the company shows the convergent validity for the model fit. 
Table 4. Discriminant Validity with Goodness of fit Measure

\begin{tabular}{|l|c|c|c|}
\hline \hline \multicolumn{1}{|c|}{ Criteria } & Acceptance Criteria & Model Fit Value & Grade \\
\hline \hline CMIN/df & $>1 \&<3$ & 1.946 & Excellent \\
\hline GFI & $\geq 0.90$ & 0.638 & Excellent \\
\hline SRMR & $<0.08$ & 0.056 & Excellent \\
\hline AGFI & $\geq 0.80$ & 0.835 & Excellent -87 \\
\hline NFI & $\geq 0.90$ & 0.858 & Excellent \\
\hline CFI & $>0.95$ & 0.965 & Acceptable \\
\hline RMSEA & $<0.06$ & 0.080 & Excellent \\
\hline PClose & $>0.05$ & 0.05 & Excellent \\
\hline \hline
\end{tabular}

Note: $\mathrm{N}=150$, CMIN $=\chi^{2}$ Value, $\mathrm{df}=$ degrees of freedom, GFI $=$ Goodness of fit Indices, SRMR $=$ Standardized root mean square residuals, AGFI = Adjusted goodness of fit indices, NFI = Normed fit index, CFI = Comparative fit Index, RMSEA = root mean square error of approximation, $\mathrm{P}$ Close $=$ Overall model fit three factors ( 9 items),$\chi^{2}=$ Chi Square Discrepancy .

S o u r c e s: AMOS 20 Output.

Discriminant validity of the scale specify the degree to which a construct is dissimilar from other constructs (Hair et al., 2016). There are two methods are castoff by the researchers for examining the discriminant validity which shows the interdependence among the various construct that have been taken into the study. Firstly, the correlation coefficient among the different sets of constructs in the dimension model which are also ideally different should not be high. This is because the different set of items are castoff for computing the different constructs. These items are predictable to be different from each other thus should not correlated too powerfully (Trochim, 2006). Second the average variances extracted (AVE) guesses of the individual constructs in the measurement model are higher than the maximum common variances of each construct and the square root of AVE should be higher than the correlations among the constructs. Table 4 indicates discriminant validity value given by Hu Banter to check the model fit among the three construct affecting the behavior of the investors in the Gujarat state. It can be concluded from the model that it is best fitted with the excellent category accept one criterion. The value of goodness of fit is also positive, which is an indicator of best model fit to 
check the mediation effect among the factors affecting the behavior of investors in the market.

Table 5. Mediation Effect through Direct and Indirect Standardized Effect Model

\begin{tabular}{|l|l|l|l|}
\hline \hline \multicolumn{1}{|c|}{ Effect } & $\boldsymbol{\alpha}$ value & Significance & Interpretation \\
\hline \hline Indirect Effect & $0.011^{* *}$ & Significant & Mediation \\
\hline Direct Effect & $0.012^{* *}$ & Significant & Partial Mediation \\
\hline \hline
\end{tabular}

N o te : Indirect Effect Mediation if $\alpha<0.05^{* *}$.

Then, Direct Effect Complete Mediation if $\alpha>0.05$, Direct Effect Partial Mediation if $\alpha<0.05$.

S o u r c es: AMOS 20 Output.

A mediating effect is shaped once a third variable or construct interferes between two other related construct. Table 5, indicates the Mediation effect measurement given by Baron \& Kenny. It can be inferred that, the Standardized Indirect values is 0.011 which is $<0.05$ which shows the mediation effect of Location of the company on Company information to see the impact on IPO issue while taking decision by the investors to invest in a particular stock in the Gujarat state of India. Once the mediation effect has been checked Standardized Direct effect under the Bootstrap Confidence Interval Two tail Significance Level and the value is $0.012<0.05$ which is significant and it proves Partial Mediation effect of location of Company on Company information and IPO issues. Direct effects are the relationship connecting two constructs with a single dart; indirect effects are those relationships that include a sequence of relationships with at least one superseding construct tangled. Thus, an indirect effect is an arrangement of two or more direct effects (complex path) that are characterized visually by multiple arrows. This indirect effect is characterized as the mediation effect.

\section{IIICLNCLION}

In the country like India where financial market are at under development stage and Investors are not that much advance in terms of their fundamental and technical knowledge regarding the movement of the stock prices in the 
market due to which they can be easily get influenced by the other factors other than the stock prices movements which are called behavioral biases. This research paper has mainly focused to check the impact of these various behavioral biases on the investor's mindset that leads to significant movement in the stock prices in the Indian stock market in the area of Gujarat State. Behavior of investor's are getting influenced by mainly three factors out of the fifteen statements asked to the investors in this study i.e. company information, IPO issues and location of the company. From these three factors, company information is independent construct, IPO issue is dependent construct and Location of the company of plants and offices has a partial mediating effect along with company information which have the significant impact on the IPO issue of the company which can be reflected in the behavior of investors in the stock market of Gujarat state which has the significant impact on the movement of stock prices.

\section{REFERENCES}

Cronbach, L.J. (1951). Coefficient alpha and the internal structure of tests. Psychometri$k a, 16(3), 297-334$.

Grinblatt, M., \& Keloharju, M. (2001). How distance, language, and culture influence stockholdings and trades. The Journal of Finance, 56(3), 1053-1073. http://dx.doi. org/10.1111/0022-1082.00355.

Hair Jr, J.F., Hult, G.T. M., Ringle, C., \& Sarstedt, M. (2016). A primer on partial least squares structural equation modeling (PLS-SEM). New York: Sage Publications.

Head, K., Ries, J., \& Swenson, D. (1995). Agglomeration benefits and location choice: Evidence from Japanese manufacturing investments in the United States. Journal of International Economics, 38(3-4), 223-247. http://dx.doi.org/10.1016/00221996(94)01351-R.

Keswani, S., Dhingra, V., \& Wadhwa, B. (2019). Impact of Behavioral Factors in Making Investment Decisions and Performance: Study on Investors of National Stock Exchange. International Journal of Economics and Finance, 11(8), 80-90. http://dx.doi. org/10.5539/ijef.v11n8p80.

Kim, J.H., Lee, S.Y., Kim, C., Lim, S.L., Shin, J N., Chung, W., Yu, B.H., \& Hong, S.H. (2002). Reliability and validity of a Korean adaptation of the tinnitus handicap inventory. Korean Journal of Otolaryngology-Head and Neck Surgery, 45(4), 328-334.

Kim, K.A., \& Nofsinger, J.R. (2008). Behavioral finance in Asia. Pacific-Basin Finance Journal, 16(1), 1-7. http://dx.doi.org/10.1016/j.pacfin.2007.04.001.

Noar, S.M. (2003). The role of structural equation modeling in scale development. Structural Equation Modeling, 10(4), 622-647. http://dx.doi.org/10.1207/ S15328007SEM1004_8. 
Saravanan, S., \& Satish, R. (2014). Does IPO grading positively influence retail investors? A quantitative study in Indian Capital Market. SAMZODHANA - Journal of Management Research, 2(1), 61-73.

Sarin, V., \& Sidana, N. (2017). A Study of Perceptions of Investors Towards IPO Grading in India. International Journal of Economic Research, 14(20), 757-770.

Trochim, W.M. (2006). Convergent and discriminant validity, https://conjointly.com/ $\mathrm{kb} /$ convergent-and-discriminant-validity/ (accessed: 25.03.2011). 